\title{
Pengelolaan arsip statis di Dinas Kearsipan Daerah Provinsi Sumatera Selatan
}

\author{
Eka Apriyani ${ }^{1}$, Dinda Safira ${ }^{2}$, Rhoni Rodin ${ }^{3}$ \\ ${ }^{1,2}$ Mahasiswa Jurusan Ilmu Perpustakaan UIN Raden Fatah Palembang \\ ${ }^{3}$ Pustakawan IAIN Curup, Rejang Lebong, Bengkulu \\ Email: rhoni.rodin@iaincurup.ac.id
}

\begin{abstract}
This study aims to determine the management of static archives in the South Sumatra Archives Service. The research method used is a qualitative approach using a survey design type to obtain valid data by conducting observations and interviews directly to the speakers and the results using descriptive analysis. Management of static records carried out at the South Sumatra Archives Service covers the activities of collecting static records, acquisition of static records, archival search lists (DPA), management of static records, maintenance of static records, access or static archive retrieval systems and archival information systems. In the management of static records carried out at the South Sumatra Archives Service, it is quite good, but it is still constrained by human resources, funds and lack of awareness of agencies under the archives service that must submit static records that have a use and historical value so that this becomes one of the obstacles in managing records in the South Sumatra Regional Archives Service.
\end{abstract}

Keywords: Archive Management, Static Record, South Sumatra Archives Service

\begin{abstract}
ABSTRAK
Penelitian ini bertujuan untuk mengetahui pengelolaan arsip statis di Badan Kearsipan Sumatera Selatan. Metode penelitian yang digunakan adalah pendekatan kualitatif dengan menggunakan tipe desain survei untuk mendapatkan data-data yang valid dengan melakukan observasi dan wawancara langsung kepada narasumber dan hasilnya menggunakan analisis deskriptif. Pengelolaan arsip statis yang dilakukan di Dinas Kearsipan Sumatera Selatan meliputi kegiatan pengumpulan arsip statis, akuisisi arsip statis, daftar pencarian arsip (DPA), pengelolaan arsip statis, pemeliharaan arsip statis, akses atau sistem temu kembali arsip statis serta sistem informasi kearsipan. Dalam pengelolaan arsip statis yang dilakukan di Dinas Kearsipan Sumatera Selatan sudah cukup baik, tetapi masih terkendala oleh SDM, dana dan kurangnya kesadaran instansi dibawah dinas kearsipan yang harus menyerahkan arsip statis yang memiliki nilai guna dan sejarah sehingga hal ini menjadi salah satu kendala dalam pengelolaan arsip di Dinas Kearsipan Daerah Sumatera Selatan.
\end{abstract}

Kata kunci: Pengelolaan arsip, Arsip statis, Dinas kearsipan sumatera selatan

\section{A. PENDAHULUAN}

Arsip adalah gudang memori, memberikan bukti yang andal untuk mengetahui historis di masa lalu bagi yang membutuhkan informasi di masa sekarang atau yang akan datang (Jimerson 2013). Kearsipan berperan penting dalam kegiatan administrasi, sebagai pusat ingatan dan sumber informasi dalam rangka melakukan kegiatan perencanaan, penganalisaan, perumusan kebijakan, pengambilan keputusan, pembuatan laporan, penilaian, pengendalian dan pertanggungjawaban dengan setepat-tepatnya (Rachmadi 
2016). Dengan demikian dapat dipahami bahwa "All archiving laws or regulations are basically for the existence of archives and archives very important for society, government and the Indonesian Nation" (Rodin 2019). Semua undang-undang atau peraturan pengarsipan pada dasarnya untuk keberadaan arsip dan arsip sangat penting bagi masyarakat, pemerintah dan Bangsa Indonesia. Disinilah letak urgensinya pengelolaan arsip secara baik dan teratur sesuai dengan prosedur dan regulasi yang berlaku.

Pengelolaan arsip statis dilaksanakan untuk menjamin keselamatan arsip sebagai pertanggungjawaban nasional bagi kehidupan bermasyarakat, berbangsa, dan bernegara. Dalam rangka pengelolaan arsip statis setiap lembaga kearsipan sesuai dengan wilayah kewenangannya akan selalu berupaya menambah atau memperluas khazanah arsip statisnya dari sumber arsip (pencipta arsip atau pemilik arsip), baik melalui proses penyerahan karena kewajiban pencipta arsip ataupun proses ganti rugi oleh lembaga kearsipan kepada pihak yang menyerahkan arsip statisnya. Pencipta arsip sebagai salah satu sumber keberadaan arsip dapat berbentuk lembaga/badan tingkat pusat dan daerah (pemerintah, swasta) ataupun perseorangan (negarawan, budayawan) yang memiliki pengaruh secara nasional dan lokal. Arsip statis merupakan jenis arsip yang memiliki nilai guna kesejarahan dan sebagai bahan pertanggungjawaban nasional atas pelaksanaan kehidupan bermasyarakat, berbangsa, dan bernegara. Dalam konteks penyelenggaraan kearsipan nasional, keberadaan arsip statis sejatinya bukan lagi berada di lingkungan pencipta arsip tetapi berada di lembaga kearsipan sebagai organisasi kearsipan yang memiliki fungsi dan tugas mengelola arsip statis dari berbagai pencipta arsip ataupun pemilik arsip untuk dimanfaatkan bagi kepentingan publik, ilmu pengetahuan, dan kesejahteraan rakyat (S. M. Rahmah 2018).

Dengan jumlah arsip yang banyak maupun kondisi dokumen yang terkadang tidak baik, maka ditemukan kesulitan dalam mengelola arsip-arsip tersebut. Kesulitan tersebut muncul dari segi fasilitas tempat penyimpanan maupun kondisi arsip-arsip yang sudah rapuh. Untuk memecahkan masalah tersebut, diperlukan pengelolaan dan perawatan yang tepat kepada arsip statis yang menjadi dokumen penting bagi pemerintah, swasta, maupun perorangan.

Arsip daerah provinsi adalah lembaga kearsipan berbentuk satuan kerja perangkat daerah yang melaksanakan tugas pemerintahan di bidang kearsipan pemerintahan daerah provinsi yang berkedudukan di ibu kota provinsi. Arsip daerah provinsi merupakan lembaga kearsipan daerah provinsi yang wajib dibentuk oleh pemerintahan daerah provinsi (Azmi 2016). Begitu juga dalam konteks Arsip Daerah Propinsi Sumatera Selatan ini, artinya lembaga ini melaksanakan tugas pemerintahan di bidang kearsipan pemerintahan daerah provinsi yang berkedudukan di Propinsi Sumatera Selatan.

Meskipun kearsipan berperan penting dalam administrasi, ironisnya saat ini masih banyak kantor-kantor (pemerintah maupun swasta) yang belum melaksanakan penataan arsip dengan baik, sering kita jumpai arsip-arsip ditumpuk di dalam gudang dan dibiarkan terbengkalai begitu saja. Hal inilah yang menjadikan penerapan suatu sistem kearsipan pada suatu instansi menjadi tidak optimal terlebih lagi karena jika dilakukan proses pencarian kembali akan sangat menyulitkan bagi pihak-pihak yang mempunyai kepentingan terhadap arsip tersebut. Oleh karena itu diperlukan sebuah langkah untuk mengelola arsip statis agar menjadi sebuah informasi yang dapat ditemu-kembalikan sewaktu-waktu jika diperlukan oleh para pencari/ pengguna arsip.

Berdasarkan uraian di atas, maka yang menjadi rumusan masalah dalam kajian artikel ini adalah bagaimana pengelolaan arsip statis di Dinas Kearsipan Daerah Provinsi Sumatera Selatan? Sedangkan tujuan dari kajian artikel ini adalah untuk mendeskripsikan 
dan menganalisis bagaimana pengelolaan arsip statis di Dinas Kearsipan Daerah Provinsi Sumatera Selatan.

\section{B. TINJAUAN PUSTAKA}

Pengelolaan arsip statis merupakan sebuah kegiatan untuk mengolah arsip inaktif yang telah diterima lembaga kearsipan dari pencipta arsip agar menjadi sebuah informasi yang dapat dimanfaatkan oleh masyarakat ataupun lembaga yang membutuhkan informasi tersebut ke depannya.

Pasal 1 angka 26 Undang-Undang Nomor 43 Tahun 2009 tentang Kearsipan mendefinisikan bahwa pengelolaan arsip statis adalah proses pengendalian arsip statis secara efisien, efektif, dan sistematis yang meliputi akuisisi, pengolahan, preservasi, pemanfaatan, pendayagunaan, dan pelayanan publik dalam suatu sistem kearsipan nasional (Penyusun 2009).

Arsip statis memiliki berbagai pengertian, diantanya yaitu:

a. Dalam Undang-undang Nomor 43 Tahun 2009, yang dimaksud dengan arsip statis adalah arsip yang dihasilkan oleh pencipta arsip karena memiliki nilai guna kesejarahan, telah habis retensinya, dan berketerangan dipermanenkan yang telah diverifikasi baik secara langsung maupun tidak langsung oleh Arsip Nasional Republik Indonesia dan / atau lembaga kearsipan (Rosalin 2017).

b. Menurut Wursanto "arsip statis sering disebut archive atau permanent record, yaitu arsip-arsip yang tidak secara langsung dipergunakan dalam penyelenggaraan administrasi negara."

c. Menurut Sedarmayanti "arsip statis adalah arsip yang tidak dipergunakan secara langsung untuk perencanaan, penyelenggaraan kehidupan kebangsaan pada umumnya maupun untuk penyelenggaraan sehari-hari administrasi negara (wardah 2016).

Arsip statis sering juga disebut archive atau permanent record yaitu arsip-arsip yang tidak secara langsung dipergunakan dalam penyelenggaraan administrasi negara. Arsip abadi (archive) warkat-warkat vital yang akan disimpan selama-lamanya, maka arsip ini mempunyai taraf nilai yang abadi. Dengan demikian yang termasuk arsip statis adalah abadi (archive). Arsip statis terdapat di Arsip Nasional Republik Indonesia Pusat ( Arsip Nasional Pusat) dan Arsip Nasional Republik Indonesia Daerah ( Arsip Nasional Daerah ). Arsip statis merupakan pertanggung jawaban Nasional bagi kegiatan Pemerintah Indonesia dan nilai gunanya penting untuk generasi yang akan datang. Yang mengambil tanggung jawab atas pngumpulan, pelestarian dan menyediakan untuk penelitian rekod yang dipilih untuk dilestarikan karena memiliki nilai historis adalah seorang arsiparis (Sulistyo-Basuki 2015).

Jadi, arsip statis adalah arsip dihasilkan oleh pencipta arsip karena memiliki nilai guna kesejarahan, telah habis retensinya yang tidak digunakan secara langsung dalam penyelenggaraan administrasi negara tetapi perlu disimpan karena memiliki nilai sejarah yang harus disimpan.

Pengelolaan arsip harus dilaksanakan secara efektif agar berdampak positif terhadap produktivitas organisasi. Pengelolaan arsip yang efektif akan menyebabkan pelayanan kepada pengguna menjadi lebih baik, produktivitas pegawai meningkat, menghemat tenaga kerja dan mempermudah akses arsip dan informasi oleh semua pegawai yang membutuhkan (Sutirman 2015). 


\section{a) Hubungan Arsip Dinamis dengan Arsip Statis}

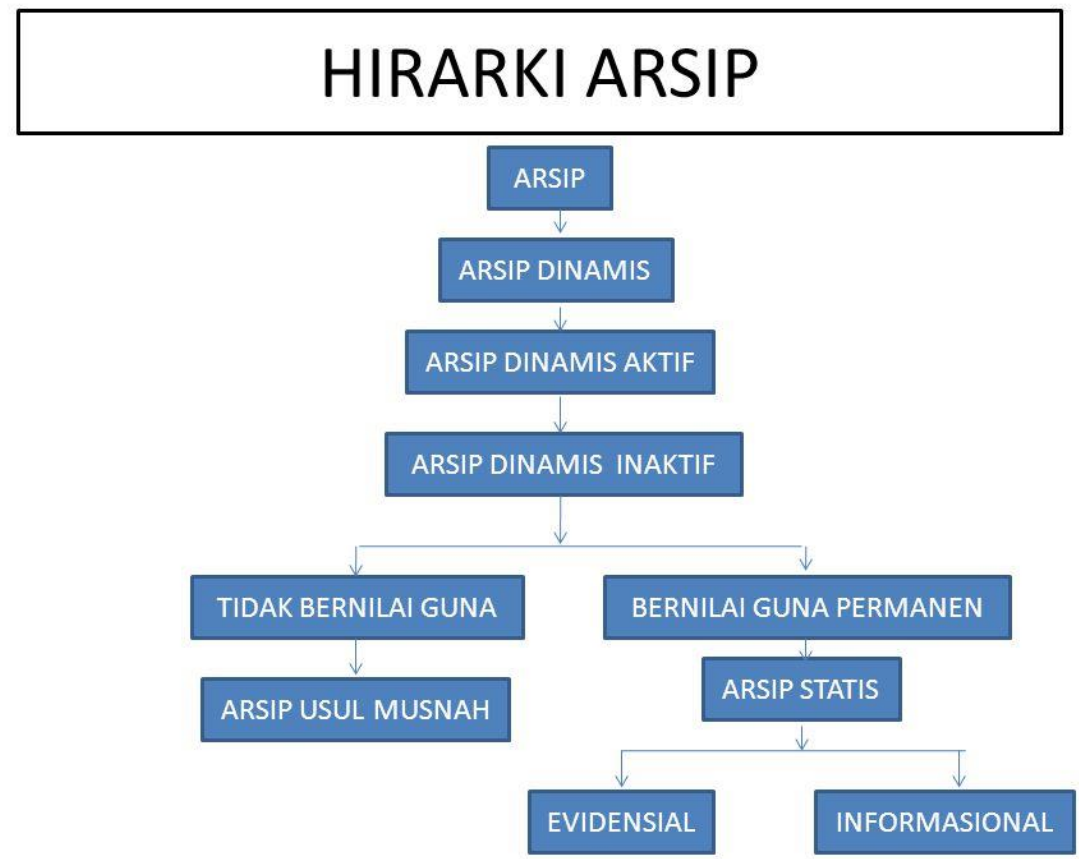

Gambar 1: herarki arsip

Sumber: www.google.com

Jika dilihat dari herarki arsip tersebut menunjukkan kurang tegasnya pembagian pertanggungjawaban seorang recods manajer (orang yang menangani arsip dinamis) dan arsiparis. Maka dari itu diperlukan sebuah koordinasi untuk menghindari teradinya kesalahan dalam penanganan sebuah arsip. Koordinasi ini berkaitan dengan informasi tentang masa simpan arsip ataupun tentang kondisi fisik arsip. Masa simpan arsip inaktif jika sudah habis masa simpannya akan dilakukan penilaian ataupun penyusutan kepada arsip tersebut, apakah akan dimusnahkan atau dilestarikan.

Jika arsip tersebut memiliki nilai historis dan perlu dilestarikan maka arsip akan memasuki masa statis. Untuk melakukan penyusutan ini perlu adanya kerjasama antara petugas dari kedua bidang, sehingga penilaian akan maksimal. Setelah selesai penilaian dan penyusutan maka akan diketahui mana arsip yang akan dilestarikan. Dari hal inilah dimulainya proses pengelolaan arsip statis yang dimulai dari kegiatan akuisisi oleh lembaga kearsipan yang menangani arsip statis.

Jadi, berdasarkan hirarki arsip dapat diketahui bahwa arsip statis didapatkan atau dihasilkan dari arsip dinamis yang masa penggunaannya sudah berkurang, kemudian dilakukan penilaian dan penyusutan, jika tidak memiliki nilai guna akan dimusnahkan dan apabila masih memiliki nilai guna akan dilestarikan dan berubah menjadi arsip statis yang penggunaannya tidak secara langsung.

\section{b) Pengelolaan Arsip Statis}

Arsip statis merupakan bagian dari sebuah informasi yang patut untuk diorganisasikan dan dijaga dengan baik. Berikut ini merupakan kegiatan pengelolaan arsip statis dilihat dari gambar daur hidup arsip statis: 


\section{MANANEMEN ARSIP STATIS}

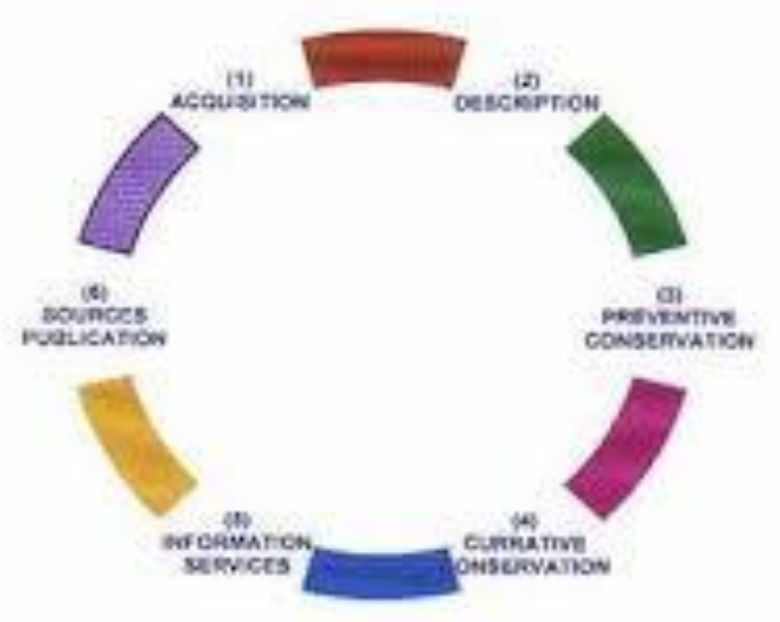

Gambar 2 : Daur Hidup Arsip Statis.

Sumber: www.google.com

Dari gambar diatas dapat diketahui bahwa kegiatan daur hidup arsip statis dimulai dari kegiatan acquisition, description, preventive, concervation, curative concervation, information service, and source publication. (akuisisi, deskripsi, pemeliharaan, perawatan, penggunaan, dan sumber publikasi) (Sutirman 2015).

Jadi sudah jelas bahwa kegiatan pengelolaan arsip statis berdasarkan daur hidup arsip statis dimulai dari kegiatan akuisisi, deskripsi, pemeliharaan, perawatan, penggunaan serta sumber publikasi.

\section{c) Pemanfaatan Teknologi}

Seiring dengan perkembangan zaman dan ilmu pengetahuan, membawa kemudahan dalam pelaksanaan tugas-tugas kearsipan. Dengan semakin banyaknya atau besarnya volume data yang harus dikumpulkan, diolah, dianalisa, diinterpretasikan, disimpan dan didistribusikan kepada pengguna, maka pada abad teknologi modern seperti sekarang ini, terbukti bahwa penanganan informasi akan lebih efisien bila dilakukan dengan menggunakan alat-alat elektronik sebagai bukti perkembangan zaman.

\section{METODE PENELITIAN}

Jenis penelitian ini adalah deskriptif dengan pendekatan kualitatif. Pendekatan kualitatif bertujuan untuk memahami objek yang diteliti secara mendalam. Penelitian kualitatif bertujuan mencakup informasi tentang fenomena utama yang dieksplorasi dalam penelitian, partisipan penelitian dan lokasi penelitian (Rukajat 2018). Penelitian dilakukan pada tanggal 11 Maret 2019 sampai 29 Maret 2019 di Dinas Kearsipan Daerah Propinsi Sumatera Selatan dengan menggunakan tipe desain survei untuk mendapatkan data-data yang valid dengan melakukan observasi dan wawancara langsung kepada narasumber dan hasilnya menggunakan analisis deskriptif yaitu dilakukan pada saat melakukan penelitian dilapangan ataupun setelah semua data terkumpul (Emzir 2015). 


\section{HASIL DAN PEMBAHASAN}

\section{1) Pengumpulan Arsip Statis}

Menurut Muhamad Sidiq Paesol Arsiparis Dinas Kearsipan Sumatera Selatan, awalnya arsip itu terbagi dua yaitu arsip dinamis dan arsip statis. Arsip dinamis dibagi menjadi arsip aktif dan inaktif. Arsip aktif adalah arsip yang frekuensi penggunaanya tinggi atau digunakan secara terus menerus sedangkan arsip inkatif adalah arsip yang frekuensinya telah berkurang atau menurun. Melalui kegiatan penilaian dan penataan. Pertama dari pengelolaan arsip inaktif, kemudian dilakukan penyusutan terhadap arsip inaktif, untuk arsip yang telah habis jadwal retensinya dan tidak memiliki nilai guna akan dimusnahkan dan yang masih memiliki nilai historis akan menjadi arsip statis. Penyusutan arsip dilakukan berdasarkan jadwal retensi 10 tahun keatas. Setelah pengumpulan arsip statis diketahui, selanjutnya arsip akan melalui kegiatan akuisisi (Paesol 2019). Arsip statis yang diserahkan oleh pencipta arsip kepada lembaga kearsipan harus merupakan arsip yang autentik, terpercaya, utuh, dan dapat digunakan.

Arsip yang diserahkan kepada dinas kearsipan sumatera selatan harus sudah terdata dan tertata dengan baik sehingga petugas hanya tinggal mencocokkannya saja. Kemudian jika tidak cocok akan dicoret dan akan dibuatkan berita acara. Sebelum adanya UU No 43 Tahun 2009 tentang Kearsipan memang arsip yang diserahkan ke dinas kearsipan berupa arsip kertas yang dimasukkan kedalam karung, hal ini membuat dinas kearsipan kewalahan karena harus menge-check satu persatu untuk melihat keautentikan, keterpercayaan, keutuhan dan kegunaan sebuah arsip. Karena terlalu banyak arsip yang datang, sehingga terkadang arsip yang penting tidak dilestarikan atau lembaran bagiannya hilang.

Jadi, kegiatan pengumpulan arsip yang dilakukan di Dinas Kearsipan Sumatera Selatan dilakukan mulai dari arsip inaktif yang sudah melalui penilaian dan penataan serta penyusutan berdasarkan JRA, jika arsip yang masih memiliki nilai guna dan nilai historis maka akan menjadi arsip statis. Kemudian akan dilakukan kegiatan akuisisi.

\section{2) Akuisisi}

Menurut Peraturan Pemerintah No. 28 Tahun 2012 Akuisisi arsip statis adalah proses penambahan khasanah arsip statis pada lembaga kearsipan yang dilaksanakan melalui kegiatan penyerahan arsip statis dan hak pengelolaannya dari pencipta arsip kepada lembaga kearsipan. Pada saat melakukan serah terima arsip statis disertai dengan berita acara dan daftar arsip statis yang diserahkan.

Dalam rangka pelaksanaan akuisisi arsip statis lembaga kearsipan wajib membuat DPA (Daftar Pencarian Arsip) terhadap arsip yang belum diserahkan oleh pencipta arsip (Indonesia 2012).

Hal serupa juga dilakukan di Dinas Kearsipan Sumatera Selatan, dalam melakukan kegiatan akuisisi mereka selalu mengadakan berita acara agar tidak adanya simpang siur dan sebagai bukti yang legal dalam suatu kegiatan. Berita acara dibuat agar Dinas Kearsipan memiliki bukti jika sewaktu-waktu ada yang menuntut.

\section{3) Membuat DPA (Daftar Pencarian Arsip)}

Pembuatan DPA harus sesuai dengan asal usul dan asas aturan asli. Menurut Peraturan Pemerintah Nomor 28 Tahun 2012, pengertian DPA adalah daftar berisi arsip yang memiliki nilai guna kesejarahan baik yang telah diverifikasi secara langsung maupun tidak langsung oleh lembaga kearsipan dan dicari oleh lembaga kearsipan serta diumumkan kepada publik.

Peraturan pemerintah Nomor 28 tahun 2012 pasal 94 menerangkan bahwa DPA sekuran-kurangnya memuat: 

a. pencipta arsip;
b. nomor arsip;
c. kode klasifikasi;
d. uraian informasi arsip;
e. kurun waktu;
f. jumlah arsip; dan
g. keterangan (Indonesia 2012).

Pembuatan daftar pencarian arsip berdasarkan kartu-kartu deskripsi yang kemudian dikelompokkan berdasarkan seri arsip di instansi yang bersangkutan. Seri arsip tersebut disusun dalam sebuah skema dijadikan dasar pengelompokan kartu, yang kemudian dituangkan ke dalam bentuk daftar yang berupa:

1. Indeks Nomor/Angka, Abjad, Subyek,

2. Indeks Nama untuk nama (orang, tempat wilayah).

\section{4) Pengelolaan arsip}

Pengelolaan arsip statis dilakukan melalui kegiatan menata informasi arsip statis, menata fisik arsip dan menyusun sarana bantu temu balik arsip statis. Kegiatan pengelolaan arsip statis di Dinas Kearsipan Sumatera Selatan dilakukan mulai dari kegiatan inventarisasi arsip statis, kemudian diberi label yang berisi tentang arsip apa yang terdapat didalamnya (atau dalam konteks perpustakaan sama halnya dengan pemberian nomor panggil). Kemudian arsip-arsip statis yang sudah diberi label akan disimpan di dalam box yang diberi lubang sebagai ventilasi udara untuk menjaga arsip tersebut.

Arsip yang telah dimasukkan kedalam box yang telah diberi label kemudian disimpan di dalam lemari. Selanjutnya, untuk penempatannya disusun berdasarkan angka sehingga mudah untuk temu kembali terhadap arsip.

Menurut Quible, ada tiga sistem penyimpanan dokumen yang dapat dipertimbangkan sesuai dengan keadaan organisasi, yaitu penyimpanan terpusat (sentralisasi), penyimpanan desentralisasi, dan kombinasi kedua sistem. Untuk dokumen yang bersifat inaktif dan tidak akan dimusnahkan akan menjadi sebuah dokumen atau arsip statis. Dokumen atau arsip statis dalam sebuah organisasi penyimpanannya dipindahkan ke dalam depo arsip. Dengan merujuk kajian teori tentang sistem penyimpanan yang telah dijabarkan, maka dapat disimpulkan bahwa pemilihan sistem penyimpanan arsip sangat bergantung pada kebutuhan, kemampuan dan kemauan dari organisasi itu sendiri (Munir 2007).

Untuk penyimpanan arsip di Dinas Kearsipan Sumatera Selatan berada di tempat khusus. Untuk arsip inaktif disimpan pada record center yang terdiri dari 3 gudang. Sedangkan untuk arsip statis disimpan di ruang depo arsip yang terdiri hanya satu gudang yang berjumlah 8.976 dan untuk arsip inaktif sekitar 25.000 lebih.

\section{5) Pemeliharaan Arsip}

Menurut Sulistiyo-Basuki (1992:231), tata kerja pemeliharaan arsip sebagai berikut: pengaturan arsip di rak, pembersih dan penghilang debu, dan pembetulan letak arsip. Pengaturan arsip di rak dalam bahasa Inggris dikenal dengan shelving. Kegiatan ini dilakukan secara hati-hati untuk menghidari terjadi nya keruskan pada arsip. Pengaturan arsip di rak disusun secara berurut untuk memenuhi kebutuhan pemakai (A. g. Rahmah 2013).

Menurut peraturan pemerintah Nomor 28 tahun 2012, preservasi arsip statis dilakukan dengan cara preventif yaitu dengan melakukan penyimpanan, pengendalian hama terpadu, reproduksi dan perencanaan menghadapi bencana (Indonesia 2012). Untuk 
kegiatan pemeliharaan di Dinas Kearsipan Sumatera Selatan sudah dilakukan dengan baik, diantaranya yaitu:

1) Mengatur arsip di rak, mereka sudah melakukan pemeliharaan arsip dengan menyusunnya kedalam sebuah rak. Kemudian tinggi rak diatur sekitar 30-40 cm agar tidak terjadi penguapan dari lantai sehingga menyebabkan arsip menjadi lembab. Berikut tampilan rak arsipnya.

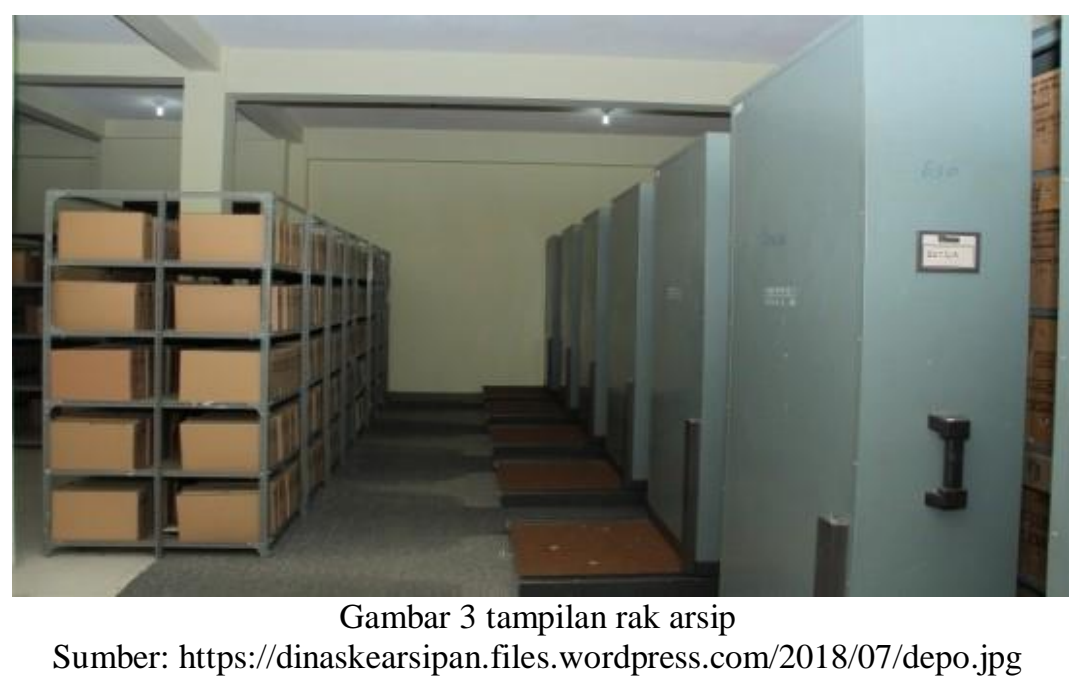

2) Reproduksi, dinas kearsipan melakukan preservasi reproduksi dengan melakukan alih media yang dilakukan dengan memperhatikan kondisi fisik dan nilai informasi dan hasil alih medianya diautentiskan dengan yang berbentuk fisik. Sebagai contoh arsip-arsip lama sebelum kemerdekaan masih terpelihara karena dilalukan pemeliharaan dan alih media. Berikut tampilannya.

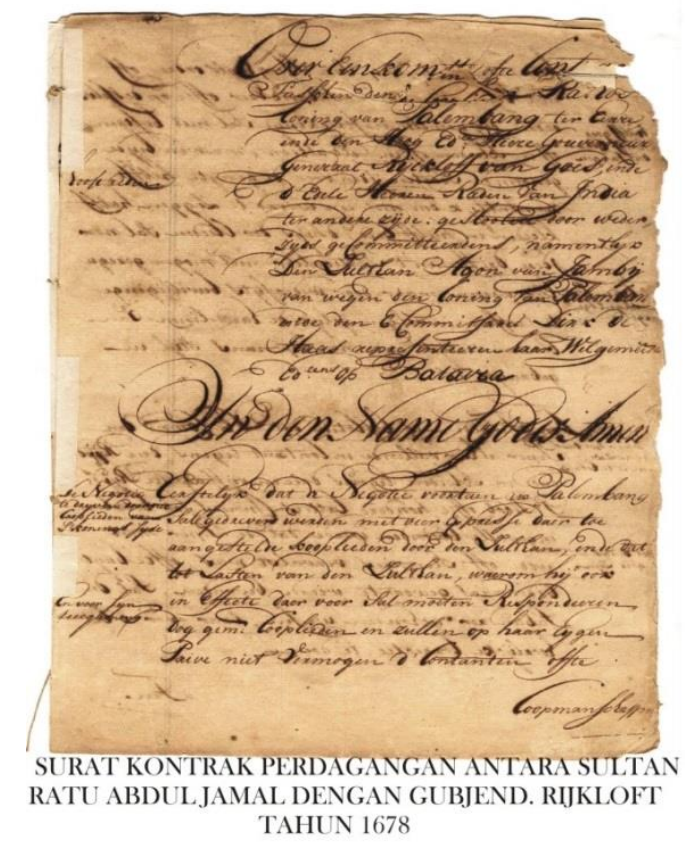

Gambar 4 conton tampilan arsip yang bernılai sejarah

Sumber: https://dinaskearsipan.wordpress.com/2018/07/11/sarana-prasana-dan-kinerja-dinaskearsipan-provinsi-sumatera-selatan/ 
3) Pembersih dan menghilangkan debu, mereka melakukan pembersihannya secara rutin minimal satu minggu satu kali menyapu ruangan dan membersihkan debu dengan menggunakan bulu ayam

4) Membasmi perusak arsip seperti hama, jamur dengan melakukan vacum 1 bulan satu kali dan fumigasi 6 bulan satu kali.

5) Ruangan, untuk menjaga arsip dinas kearsipan selalu menjaga ruangan agar matahari tidak masuk secara langsung kedalam ruangan dan menjaga suhu ruangan sekitar $18-22^{\circ} \mathrm{c}$ serta kelembaban ruangan 12-18 RH.

Kegiatan pemeliharaan atau perawatan terhadap arsip yang ada di dinas kearsipan daerah sumatera selatan dilakukan oleh lembaga kearsipan tersebut dengan anggaran dari APBD.

Untuk menyelamatkan arsip yang tersedia di dinas kearsipan sumatera selatan menduplikat arsip statis atau mengalih mediakan yaitu dengan disimpan di dalam komputer maupun flasdisk.

\section{6) Akses Arsip Statis}

Akses arsip statis sesuai dengan UU No 43 Tahun 2009 pasal 64 bahwa lembaga kearsipan wajib menjamin kemudahan akses arsip statis bagi kepentingan pengguna arsip. Lembaga kearsipan melaksanakan pelayanan berdasarkan norma, standar, prosedur dan kriteria pelayanan yang ditetapkan oleh ANRI serta menyediakan fasilitas untuk kepentingan akses sesuai dengan ketentuan peraturan perundang-undangan.

Menyikapi hal ini maka diperlukan suatu alat yang menunjukkan dimana arsip-arsip tersebut disimpan sebagai akses untuk mendapatkan informasi tentang arsip statis. Information retrieval system (IRS) adalah sistem yang dapat menyimpan, mengambil dan memelihara informasi. Informasi memiliki banyak jenis seperti teks (termasuk data numerik dan tanggal), audio, video dan multimedia lainnya. Pemodelan pengambilan informasi sangat penting untuk membantu peneliti dalam merancang dan mengimplementasikan sistem informasi aktual yang efisien. Pemodelan matematika dapat digunakan dalam beberapa domain seperti pendidikan, medis, ilmu matematika .... dan lain-lain (Doaa 2018).

Alat temu kembali atau retrival arsip dapat berupa kode, indeks, petunjuk silang, klasifikasi dan lain sebagainya. Untuk alat temu kembali informasi di Dinas Kearsipan Daerah Sumatera Selatan bisa mencari melalui komputer yang didalamnya sudah terdapat data-data arsip yang disimpan di dalamnya atau melalui daftar arsip statis yang ditelusur secara manual.

\section{7) Sistem Informasi Kearsipan}

Untuk mendukung pengelolaan arsip statis dalam rangka memberikan informasi yang autentik dan utuh. Sistem Informasi Kearsipan Statis (SIKS) merupakan perangkat untuk menyusun database dan meng-up load kedalam sistem jaringan. Dengan adanya aplikasi SIKS ini layanan arsip yang semula masih menggunakan sarana manual dengan senarai, daftar, atau inventaris arsip nantinya dapat dilakukan dengan otomatis menggunakan sarana komputer, bahkan akan dihubungkan dengan Jaringan Informasi Kearsipan Nasional (JIKN) sebagai jaringan yang menghubungkan secara nasional ke seluruh wilayah Indonesia. Dengan sistem informasi kearsipan statis yaitu untuk mempercepat layanan akses arsip. Ketika kita melakukan pekerjaan secara manual atau satu persatu sedangkan arsip itu banyak, hal tersebut akan memakan banyak waktu, sedangkan banyak kegiatan yang harus dilakukan (Muhidin 2016). 
Untuk sistem informasi kearsipan di Dinas Kearsipan Sumatera Selatan sudah ada dan komputernya terletak di lantai 2. Selanjutnya, untuk kegiatan pengelolaan surat yang masuk dan keluar di Dinas Kearsipan Sumatera Selatan sudah ada, tetapi belum bisa menggunakannya karena belum ada operator yang ahli dalam mengoperasikan sistem tersebut. Oleh karena itu, Dinas Kearsipan Daerah Sumatera Selatan masih membutuhkan SDM yang ahli dalam hal tersebut. Hal ini tentunya menjadi salah satu penghambat dalam pengelolaan arsip modern yang berbasis teknologi informasi.

\section{E. KESIMPULAN}

Dari hasil penelitian yang dilakukan di Dinas Kearsipan Daerah Propinsi Sumatera Selatan dapat disimpulkan bahwa Dinas Kearsipan Daerah Propinsi Sumatera Selatan bukanlah pencipta arsip melainkan sebuah lembaga yang menyelamatkan arsip yang memiliki nilai sejarah atau nilai guna. Arsip statis yang disimpan sudah dialih-mediakan dengan dimasukkan ke dalam komputer dan flashdisk. Pemeliharaan arsip statis dilakukan dengan penataan koleksi di rak, reproduksi, pembersihan ruangan yang dilakukan secara rutin minimal seminggu sekali, fumigasi, vacum dan menata ruangan arsip agar tidak langsung terpapar matahari atau terlalu lembab. Untuk memudahkan temu kembali arsip dibuat kode klasifikasi arsip dan sarana yang bisa digunakan untuk menelusur yaitu komputer dan daftar arsip statis.

Kegiatan pengelolaan arsip statis dilakukan dengan baik, tetapi masih terdapat beberapa kendala yang dihadapi dalam pengelolaan arsip statis, diantaranya yaitu kurangnya tenaga ahli yang mampu mengoperasikan aplikasi komputer dan kurangnya kesadaran kewajiban untuk menyerahkan arsip statis pada dinas kearsipan.

Berdasarkan uraian di atas, maka yang menjadi saran dalam kajian artikel ini adalah:

1. Hendaknya meningkatkan kemampuan SDM kearsipan, menyediakan peralatan TI lebih baik, dan terus menerus melakukan pembenahan agar dapat lebih berdaya guna.

2. Perlu penyediaan anggaran untuk pengadaan tempat dan ruangan arsip statis sesuai standarisasi penyimpanan arsip statis.

3. Dinas Kearsipan Daerah Propinsi Sumatera Selatan harus lebih giat melakukan sosialisasi pentingnya penyerahan arsip statis.

\section{DAFTAR PUSTAKA}

Azmi. Deskripsi dan penataan arsip statis. Tangerang Selatan: Universitas Terbuka, 2016.

Doaa, Mabrouk. "Modeling using term depedencies and term weighting in information retrieval system.” Egyptian Computer Science Journal Vol 42 No. 3, 2018: 57-73.

Emzir. Metodologi penelitian pendidikan; kuantitatif dan kualitatif. Jakarta: Rajawali Pers, 2015.

Indonesia. Peraturan pemerintah nomor 28 tahun 2012 tentang pelaksanaan UndangUndang Nomor 43 tahun 2009. Peraturan pemerintah, Jakarta: Arsip Nasional Republik Indonesia, 2012.

Jimerson, Rendall C. "Archives and memory." OCLC System \& Services; International Digital Library Perspectives Vol. 19 Issue 3, 2013: 89-95.

Muhidin, Sambas Ali. "Pengelolaan arsip diigital." Jurnal Pendidikan Bisnis dan Manajemen, 2016: 180.

Munir, Sukoco Badri. Manajemen administrasi perkantoran modern. Surabaya: Erlangga, 2007.

Paesol, Muhamad Sidiq, wawancara oleh Eka Apriyani. (29 Maret 2019). 
Penyusun, Tim. Undang-undang Nomor 43 Tahun 2009 tentang Kearsipan. Undangundang, Jakarta: Arsip Nasional Republik Indonesia, 2009.

Rachmadi, Achmad Syarif. "Peran akuisisi arsip statis BUMN terhadap khazanah arsip statis BUMN di Indonesia." Jurnal Kearsipan Vol 7 No. 1, 2016: 4.

Rahmah, Aldona gusda \& Elva. "Pemeliharaan dan perawatan arsip statis di kantor arsip kabupaten pesisir selatan." Jurnal Ilmu Informasi Perpustakaan dan Kearsipan, 2013: 485.

Rahmah, Suci Maulina \& Elva. "Pelaksanaan akuisisi dalam rangka penyelamatan dan pelestarian arsip statis di Dinas Perpustakaan dan kearsipan Kota Padang." Jurnal Ilmu Informasi Perpustakaan dan Kearsipan Vol. 7 No. 1, 2018: 349.

Rodin, Rhoni. "Analysis of Development of Archiving Regulation from Time to Time in Indonesia." Record and Library Journal Vol 5 No. 1, 2019: 90-105.

Rosalin, Sovia. Manajemen arsip dinamis. Malang: Universitas Brawijaya Press, 2017.

Rukajat, Ajat. Pendekatan penelitian kualitatif (Qualitative Research Approach). Yogyakarta: Deepublish, 2018.

Sulistyo-Basuki. Pengantar ilmu kearsipan. Jakarta: Universitas Terbuka, 2015.

Sutirman. "Urgensi manajemen arsip elektronik." Jurnal Efisiensi Kajian Ilmu Administrasi Vol. 13 No.1, 2015: 103.

wardah, Mutiawatul. "Pengelolaan arsip dinamis." Jurnal Libria Vol. 8 No. 1 Juni, 2016: 51. 